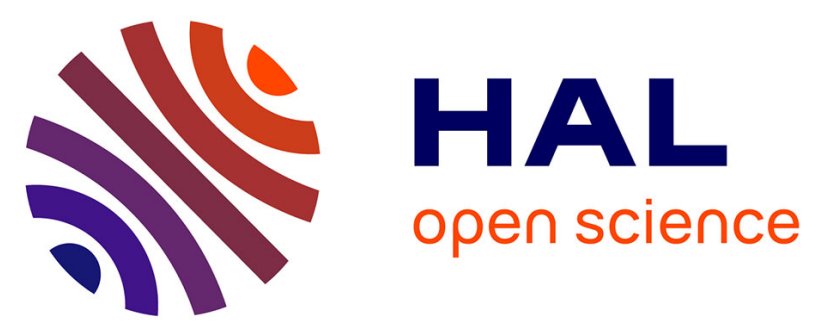

\title{
Quantitative Ultrasound of Cortical Bone in the Femoral Neck Predicts Femur Strength: Results of a Pilot Study
}

Quentin Grimal, Julien Grondin, Sandra Guérard, Reinhard Barkmann, Klaus Engelke, Claus-C. Glüer, Pascal Laugier

\section{- To cite this version:}

Quentin Grimal, Julien Grondin, Sandra Guérard, Reinhard Barkmann, Klaus Engelke, et al.. Quantitative Ultrasound of Cortical Bone in the Femoral Neck Predicts Femur Strength: Results of a Pilot Study. Journal of Bone and Mineral Research, 2013, 28 (2), pp.302-12. 10.1002/jbmr.1742 . hal-00823888

\section{HAL Id: hal-00823888 \\ https://hal.science/hal-00823888}

Submitted on 6 Jun 2013

HAL is a multi-disciplinary open access archive for the deposit and dissemination of scientific research documents, whether they are published or not. The documents may come from teaching and research institutions in France or abroad, or from public or private research centers.
L'archive ouverte pluridisciplinaire HAL, est destinée au dépôt et à la diffusion de documents scientifiques de niveau recherche, publiés ou non, émanant des établissements d'enseignement et de recherche français ou étrangers, des laboratoires publics ou privés. 


\title{
Quantitative Ultrasound of Cortical Bone in the Femoral Neck Predicts Femur Strength: Results of a Pilot Study
}

\author{
Quentin Grimal, ${ }^{1,2}$ Julien Grondin, ${ }^{1,2}$ Sandra Guérard, ${ }^{3}$ Reinhard Barkmann, ${ }^{4}$ Klaus Engelke, ${ }^{5}$ \\ Claus-C. Glüer, ${ }^{4}$ and Pascal Laugier ${ }^{1,2}$ \\ ${ }^{1}$ UPMC University Paris 06, UMR 7623, Laboratoire d'Imagerie Paramétrique, Paris, France \\ ${ }^{2}$ CNRS, UMR 7623, Laboratoire d'Imagerie Paramétrique, Paris, France \\ ${ }^{3}$ Arts $^{\mathrm{Q} 2}$ et Metiers ParisTech, Paris, France \\ ${ }^{4}$ Biomedizinische Bildgebung, Klinik für Diagnostische Radiologie, Universitätklinikum Schleswig-Holstein, Kiel, Germany \\ ${ }^{5}$ Institute of Medical Physics, University of Erlangen, Erlangen, Germany
}

\begin{abstract}
A significant risk of femoral neck (FN) fracture exists for men and women with an areal bone mineral density (aBMD) higher than the osteoporotic range, as measured with dual-energy X-ray absorptiometry (DXA). Separately measuring the cortical and trabecular FN compartments and combining the results would likely be a critical aspect of enhancing the diagnostic capabilities of a new technique. Because the cortical shell determines a large part of FN strength a novel quantitative ultrasound (QUS) technique that probes the FN cortical compartment was implemented, aimed at testing the sensitivity of the method to variations of FN cortical properties and FN strength. Nine femurs (women, mean age 83 years) were subjected to QUS to measure the through transmission time-of-flight (TOF) at the FN and mechanical tests to assess strength. Quantitative computed tomography (QCT) scans were performed to enable analysis of the dependence of TOF on bone parameters. DXA was also performed for reference. An ultrasound wave propagating circumferentially in the cortical shell, which TOF was not influenced by the properties of the trabecular compartment ${ }^{\mathrm{Q} 3}$, was measured in all specimens. Averaged TOF for nine FN measurement positions/orientations was significantly correlated to strength $\left(R^{2}=0.79\right)$ and FN cortical QCT variables: total BMD $\left(R^{2}=0.54\right)$; regional BMD in the inferoanterior $\left(R^{2}=0.90\right)$ and superoanterior $\left(R^{2}=0.57\right)$ quadrants; and moment of inertia $\left(R^{2}=0.71\right)$. The results of this study demonstrate that QUS can perform a targeted measurement of the FN cortical compartment. Because the method involves mechanical guided waves, the QUS variable is related to the geometric and material properties of the cortical shell (cortical thickness, tissue elasticity, and porosity). This work opens the way to a multimodal QUS assessment of the proximal femur, combining our approach targeting the cortical shell with the existing modality sensitive to the trabecular compartment. In vivo feasibility of our approach has to be confirmed with experimental data in patients. (c) 2012 American Society for Bone and Mineral Research.
\end{abstract}

KEY WORDS: QUANTITATIVE ULTRASOUND; FEMUR; CORTICAL BONE; STRENGTH; QCT

\section{Introduction}

$\mathrm{O}$ steoporotic hip fractures are associated with high mortality and morbidity rates, as well as high treatment costs. ${ }^{(1,2)}$ Hip fracture risk is best predicted by site-matched measurement of areal bone mineral density (aBMD) with dual-energy X-ray absorptiometry (DXA). ${ }^{(3)}$ However, aBMD alone is not sufficient to account for bone strength. A significant risk of fracture also exists for men and women with and $\mathrm{aBMD}$ higher than the osteoporotic range. ${ }^{(4-6)}$ Further, increases in aBMD following therapy do not fully explain the observed efficacy of osteoporosis drug treatments. ${ }^{(7,8)}$
The proximal femur is a complex structure composed of cortical and trabecular bone. Its mechanical strength is determined by multiple factors including material properties and structural parameters (such as size and shape of bone, cortical thickness, cortical porosity, and trabecular structure). ${ }^{(9)}$ Although bone mass as measured with DXA reflects most of these factors it does not provide an accurate picture of the strength of the proximal femur. Being a $2 D$ projectional measurement, aBMD is, for instance, unable to distinguish between differential changes occurring in cortical and trabecular bone at the femoral neck (FN). There is substantial interest in developing diagnostic means for clinical risk with improved

Received in original form May 23, 2012; revised form July 24, 2012; accepted August 13, 2012. Published online xxxx xx, 2012.

Address correspondence to: Quentin Grimal, PhD, Laboratoire d'Imagerie Paramétrique, CNRS UMR 7623, 15, Rue de I'Ecole de Medecine. 75006 Paris, France. E-mail: quentin.grimal@upmc.fr 
sensitivity to the various bone properties that affect strength and to their changes in treatment follow-up.

The cortical shell at the proximal femur determines a large part of bone strength. This is supported by experimental evidence, ${ }^{(10,11)}$ analysis of clinical data, ${ }^{(12,13)}$ and finite element modeling, which indicate that the FN cortex supports at least $50 \%$ of the load borne by the proximal femur. ${ }^{(14)}$ Furthermore, it has been suggested that bone loss in old age is mainly cortical (and is mediated by the reduction of cortical thickness and the increase of porosity). ${ }^{(15,16)}$

Given the role played by cortical bone in the mechanical stability of the FN, an assumption was made that separately measuring the cortical and trabecular bone compartments and combining the results would be a critical aspect to enhance the diagnostic capabilities of a new technique. X-ray quantitative computed tomography (QCT) is the only technique, so far, that offers the capability of in vivo measurements of the two compartments at the hip, but radiation exposure is a limiting factor. ${ }^{(17)}$ The spatial resolution of current clinical whole-body CT scanners limits the achievable accuracy of the determination of cortical thickness to about 0.8 to $1 \mathrm{~mm} \cdot{ }^{(18,19)}$ A significant improvement in spatial resolution in the hip with current $\mathrm{CT}$ technology would require an unacceptably high radiation exposure. Regarding the prediction of fracture risk, recent studies could not demonstrate an important benefit of using QCT over DXA, ${ }^{(20,21)}$ but showed a significant contribution of cortical thickness in the prediction of fracture loads ${ }^{(10)}$ and hip fracture discrimination. ${ }^{(21)}$ Magnetic resonance imaging (MRI) may give access to enhance information of bone properties, but access to the method, as for QCT, is limited. The feasibility of in vivo quantitative ultrasound (QUS) measurements at the hip has been demonstrated, with a good clinical performance for hip fracture discrimination. ${ }^{(22,23)}$ Interestingly - and similar to results previously obtained at the finger phalanges ${ }^{(24)}-a$ thorough analysis of signals transmitted through the proximal femur suggested that different propagation pathways through the trabecular or cortical compartments could be identified, leading to the concept of multimodal QUS assessment of the proximal femur, by which both the trabecular and the cortical compartments could be assessed separately.

Simulation studies of measurements at the proximal femur QUS $^{(25)}$ predicted the existence of a guided wave propagating circumferentially exclusively in the cortical shell of the neck. Such a wave is not influenced by the trabecular compartment properties. ${ }^{(26)}$ Hence, variations of the time-of-flight (TOF) of this wave should reflect only the variations of geometric (size, cortical thickness), material (mass density, elasticity), and structural (porosity) properties of the cortical compartment. ${ }^{(24,27,28)}$ The measurement of this guided wave is all the more interesting in that the strength of the FN has been associated to bone matrix mineral content, ${ }^{(29,30)}$ cortical porosity, $^{(31)}$ and cortical thickness, ${ }^{(32,33)}$ all of these properties contributing to the propagation characteristics of the guided circumferential waves. The issue of specifically measuring ultrasonically the cortical part of the proximal femur, however, has so far not been addressed.

In this work the results from an ex vivo pilot study with a novel QUS modality that targets the cortical shell of the FN are reported. The aim was twofold: ${ }^{(1)}$ testing the concept that this
QUS modality reaches a targeted measurement of the neck cortical compartment and is sensitive to variations of its properties; ${ }^{(2)}$ assessing the potential of the modality to predict femur strength.

Nine human femurs were subjected to the following: (1) ultrasound measurements with the newly developed system dedicated to cortical bone assessment; ${ }^{(2)}$ QCT measurements to assess site-matched cortical bone properties; ${ }^{(3)}$ DXA to provide a reference; and ${ }^{(4)}$ mechanical tests to assess femur strength.

\section{Materials and Methods}

Specimen preparation

Nine left femurs from female donors aged 66 to 98 years (mean age 83 years old) were obtained from a multiorgan collection. Ethical approval for the specimens was granted by the Human Ethics Committee of the Centre du don des Corps at the University René Descartes (Paris, France). The tissue donors or their legal guardians provided informed written consent to give their tissue for investigation, in accord with legal clauses stated in the French Code of Public Health. There was no information on causes of death. Prior to measurements, femurs were cut approximately $11 \mathrm{~cm}$ below the lesser trochanter.

The femurs were kept frozen at $-20^{\circ} \mathrm{C}$ after dissection. Before QUS and mechanical measurements, which were done in Paris, femora were sent frozen to Kiel for scanning with CT. Samples were thawed before the measurements. In between the QUS and mechanical tests, which were conducted within 24 hours in Paris, the specimens were stored in the refrigerator at $+4^{\circ} \mathrm{C}$.

\section{QUS}

The FN is measured with ultrasound by through-transmission in the anteroposterior direction with a pair of identical transducers placed confocally on each side of the neck (Fig. 1). Cylindrically focused, single-element transducers (IMASONIC, Voray sur I'Ognon, France) with the following characteristics were used: center frequency $=571 \mathrm{kHz} ;-6 \mathrm{~dB}$ bandwidth $=(297-761 \mathrm{kHz})$, focal length $=50 \mathrm{~mm}$, active aperture size (transducer lateral dimension $\times$ height) $29 \times 80 \mathrm{~mm}^{2}$. In contrast to spherical focusing, which produces a peak acoustic intensity at a focal point, cylindrical focusing results in a peak intensity on a line at the focal distance. The measurement plane is defined by the transducers axis (ie, ultrasound beam axis) and the focal line. The focal line (beam height) extended over a height close to the aperture height $(80 \mathrm{~mm})$, which is larger than the FN diameter. The beam width (in a direction orthogonal to the measurement plane) measured at the focal distance by the full-width at halfmaximum was $5.2 \mathrm{~mm}$. This means that the signal at the receiver transducer results from the interaction between the incident ultrasound field and an approximately 5-mm-thick transverse cross-section of the FN. Specimens and transducers were immersed in a tank filled with water at room temperature. A pulse generator (Sofranel 5052PR; Panametrics, Sartrouville, France), used to generate spike pulses, was connected to the emitting transducer. The signal was amplified (preamplifier Data 


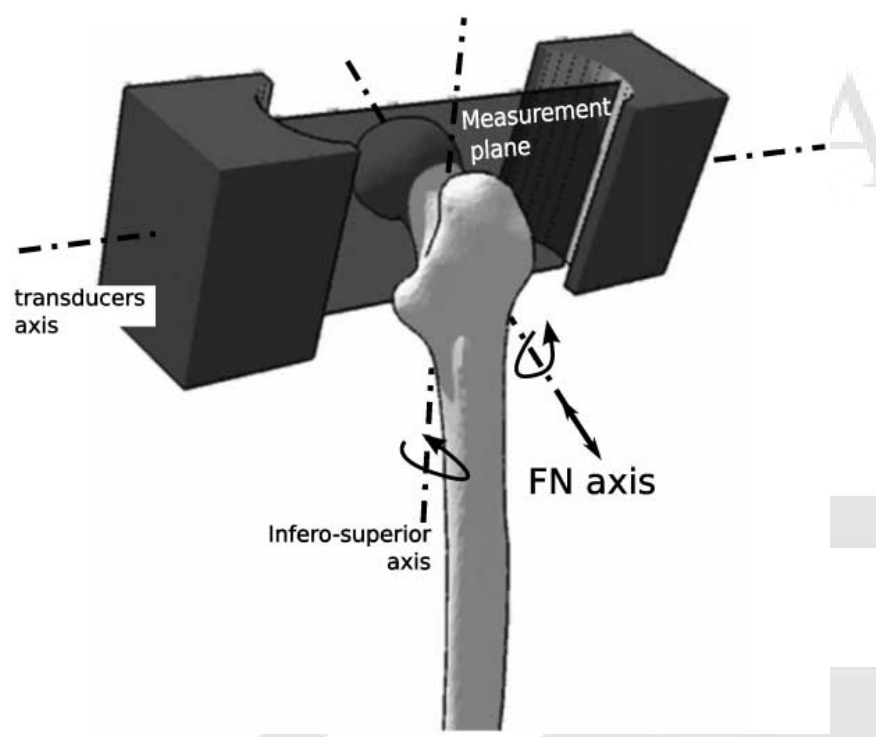

Fig. 1. Setup configuration in the "reference" position. Ultrasound waves propagate roughly parallel to the measurement plane. The orientation of the ultrasound beam coincides with the measurement plane. In the reference position, the transducers axis is aligned with the anteroposterior direction. Arrows refer to the rotation/translation motions for the positioning of the transducers in positions $\mathrm{P} 1$ to $\mathrm{P} 9$ (see ${ }^{\mathrm{Q} 4}$ text).

Precision D1000 Dual Pre-amp; Analogic, Peabody, MA, USA), digitized with an oscilloscope (TDS 1012; Tektronix, Beaverton, OR, USA) and transferred to a computer for signal processing. Each measurement consisted of several acquisitions that were averaged to attain a sufficient signal-to-noise ratio.

A system allowing translations along three orthogonal axes and rotations around these axes was designed to achieve a precise positioning of the specimen with respect to the transducers. The distance between the transducers was fixed to $100 \mathrm{~mm}$ for all the measurements. The positioning of the specimen essentially consisted in orientating the measurement plane with respect to the FN axis (see Fig. 1). The neck axis was defined as the line passing through the base of the great trochanter and the apex of the femoral head. In the "reference" position (Fig. 1), the measurement plane is positioned perpendicular to the $\mathrm{FN}$ axis, with the transducers axis aligned in the anteroposterior direction. Measurements are expected to be sensitive to the orientation and position of the ultrasound beam with respect to the neck. ${ }^{(25)}$ Accordingly, each femur was measured for nine positions of the $\mathrm{FN}$ with respect to the measurement plane:

- Positions P1, P2, and P3 were achieved by translating the transducers in a direction parallel to the neck axis; $\mathrm{P} 2$ was the reference position and $\mathrm{P} 1$ and $\mathrm{P} 3$ were $\pm 3 \mathrm{~mm}$ away from $\mathrm{P} 2$;

- Positions P4, P5, and P6 were achieved by rotating the ultrasound beam axis around the inferosuperior axis; P5 was the reference position (after repositioning following step 1) and P4 and P6 were angle positions at \pm 5 degrees from P5; and

- Positions P7, P8, and P9 were achieved by rotating the beam axis around the neck axis; P8 was the reference position (after repositioning following step 2) and P7 and P9 were angle positions at \pm 5 degrees from $\mathrm{P} 8$.

Note that the measurement configuration achieved here could in principle be achieved in vivo.

The signal recorded in the experimental configuration considered here is generally complex. It results from multiple overlapping waveforms, each corresponding to a different pathway through the tubular-like FN structure or to a different kind of guided wave ${ }^{\mathrm{Q} 5}$. ${ }^{(35)}$ Attention was focused on the TOF of the first arriving signal (FAS). The FAS is the first detectable event in the received signal transmitted through bone. It was hypothesized that the FAS is associated to the propagation of a circumferential wave guided in the cortical shell of the FN. The arrival time (TOF) of the FAS was defined as the time at which the amplitude of the waveform exceeds a threshold of 1.6 SD of the random noise of the signal before the arrival of the waves. The average value of the TOF determined at positions P1 to P9, denoted $\mathrm{TOF}_{m}{ }^{\mathrm{Q} 6}$, was calculated. In addition, reference measurements were performed in water, without the specimen, before and after the measurement of each specimen; the TOF of this reference signal is denoted $T O F_{w}$. The estimated uncertainty on TOF due to variations of water temperature was estimated to $\pm 0.3 \%$.

\section{DXA}

The aBMD $\left(\mathrm{g} / \mathrm{cm}^{2}\right)$ of all specimens was measured using DXA with a QDR 4500 A (Hologic, Waltham, MA, USA). Image acquisition and analysis were done as recommended by the manufacturer. The degassed specimens were immersed in water and measured in the anteroposterior direction. aBMD was measured for the total proximal femur (TBMDDXA) and in the neck region (NeckBMDDXA).

\section{QCT}

A 64-row CT scanner (SOMATOM Sensation; Siemens, Erlangen, Germany) in Kiel was used. A solid calibration phantom (Siemens) placed below the tank and scanned simultaneously with each femur was used to convert Hounsfield units (HU) into bone mineral density. CT scan acquisition was performed with $64 \times 1 \mathrm{~mm}$ detector collimation, $120 \mathrm{kV}, 250 \mathrm{mAs}$, and a pitch of 1. Transverse images of $1 \mathrm{~mm}$ thickness were reconstructed with a $0.7-\mathrm{mm}$ increment and a field of view (FOV) of $150 \mathrm{~mm}$, resulting in an in-plane pixel size of $293 \mathrm{~mm}$ (matrix size $=512 \times 512$ pixels). A high-resolution kernel (B40s) was used.

QCT data were analyzed in Erlangen using the dedicated software MIAF-Femur (Medical Image Analysis FrameworkFemur option; University of Erlangen, Erlangen, Germany), which was developed at the Institute of Medical Physics. The two most prominent features of this software are its 3D segmentation and analysis approach and the automatic determination of a neck coordinate system (NCS). The description of the analysis procedures has been reported. ${ }^{(36,37,10)}$

The FN region was further subdivided into four quadrants: inferoanterior (IA), inferoposterior (IP), superoposterior (SP), and superoanterior $(\mathrm{SA}){ }^{(10)}$ 
The following QCT variables, defined for the cortical part of the neck region, were used in the analysis:

- Volumetric BMD averaged over the entire FN cortical compartment (BMDCortAll);

- Volumetric BMD of the FN cortical compartment in each of the four quadrants (BMDCortSA, BMDCortSP, BMDCortlA, and $B M D$ CortIP);

- In the two inferior quadrants, average cortical bone thickness (ThickCortlA and ThickCortIP) of a 1-mm-thick slice perpendicular to the neck axis and located at the origin of the NCS. Because the superior cortex is very thin, it is expected that the thickness estimation in this region be inaccurate given the spatial resolution. Accordingly, thickness variables in the superior cortex were not included in the analysis;

- Volume of the entire FN cortical compartment (VolCortAll); and

- Density-weighted areal moment of inertia (AMIMCortAll) of the FN cortical compartment.

\section{Mechanical tests}

Mechanical tests were performed in one-legged stance configuration in order to reproduce cervical fractures consistent with clinical observations. The protocol was identical to that described, for instance, in Bousson and colleagues. ${ }^{(10)}$ Briefly, the distal portion of the shaft was fixed in a steel cylinder filled with low-melting point alloy (MCP 70; Melting \& Chemical Product, Wellingborough, UK). The shaft axis was positioned at 25 degrees to the vertical direction using a metal shim. A universal testing machine (INSTRON 5500-R; Intron Ltd, Buckinghamshire, UK) instrumented with a $100-\mathrm{kN}$ load cell was used. A vertical compressive force was applied to the femoral head at a speed of $10 \mathrm{~mm} \cdot \mathrm{min}^{-1}$ until bone fracture. A polymethylmethacrylate mold was used to distribute the applied forces on the head. The failure load (strength) $F_{\max }$ (in Newtons, N) was defined at the maximal recorded load.

\section{Data analysis}

The wave can be transmitted along different pathways. Two possible pathways are illustrated in Fig. 2: either directly in a straight line through the medullary canal (Fig. 2B, short distance, low speed of sound in marrow) or circumferentially in the cortical shell (Fig. 2B, long distance, high speed of sound in cortical bone). TOF results from a combination of distances and speed of sound. The hypothesis that the FAS is indeed associated to the propagation in the cortical shell waveguide and not to the propagation through the medullary canal needs to be validated. Toward this goal, measured TOF values for positions P1 to P9 were compared to an estimated value $T_{O} F_{d}$ of the direct wave TOF (Fig. 2B). The direct wave propagating in a straight line from the anterior to the posterior side of the neck is transmitted successively through: ${ }^{(1)}$ a water layer coupling the emitter to the specimen; ${ }^{(2)}$ the anterior cortex; ${ }^{(3)}$ the medullary canal; ${ }^{(4)}$ the posterior cortex; and ${ }^{(5)}$ finally through a second water layer coupling the specimen to the transmitter. Accordingly, TOF $F_{d}$ is the sum of the different values of TOF corresponding to the a emitter

receiver

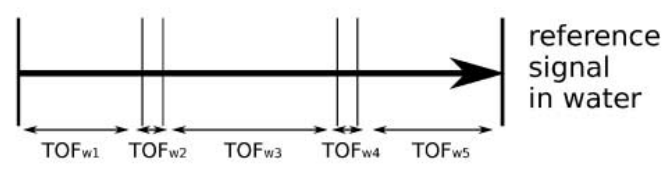

b

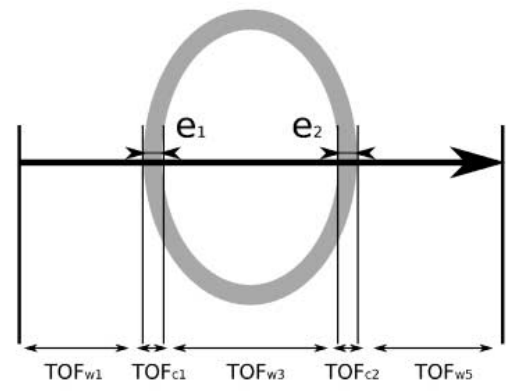

direct wave

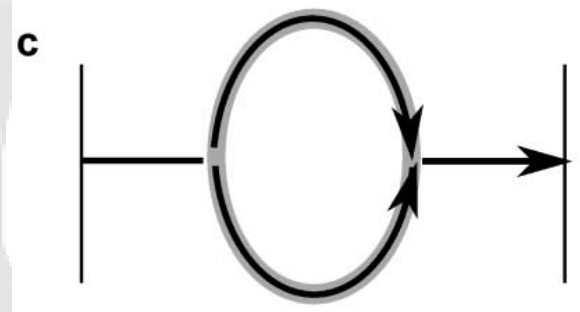

wave propagating circumferentially in the cortex

Fig. 2. Ultrasound wave paths in through-transmission and definition of partial times-of-flight (see Equation (1)). (A) propagation in water $\left(T O F_{w}\right)$ corresponding to the reference signal. $(B)$ propagation in straight line through bone (direct wave, $\left.T O F_{d}\right) ;(C)$ downward or upward propagation of a guided ultrasound wave in the cortex. $e_{1}$ and $e_{2}$ stand for thicknesses in the anterior and posterior cortex.

different layers (Fig. 2B):

$$
T O F_{d}=T O F_{w 1}+T O C_{c 1}+T O F_{w 3}+T O F_{c 2}+T O F_{w 5}
$$

where subscripts $w$ and $c$ stand for propagation paths in water (speed of sound $V_{w}$ ) and cortical bone (speed of sound of bulk longitudinal waves $V_{c}$ ), respectively. The literature shows that the speed of sound in water and marrow are very $\operatorname{similar}^{38}$; a good estimate of TOF through the marrow-filled medullary canal is thus $T O F_{w 3}$, where the speed of sound in water is taken in place of the speed of sound in marrow. For the calculations, $V_{c}=4000 \mathrm{~m} / \mathrm{s}$ and $V_{w}=1500 \mathrm{~m} / \mathrm{s}$ were used. ${ }^{(27)}$ The TOF difference between the reference signal in water $\left(T_{O} F_{w}\right.$ Fig. $2 A$ ) and the direct wave (TOF ${ }_{d}$ Fig. $2 B$ ) is as follows:

$$
\begin{gathered}
\Delta \text { TOF }_{d}=\text { TOF } w-\text { TOFd }=\text { TOFW } 2+\text { TOFW } 4-\text { TOFC } 1-\text { TOF } 2 \\
\Delta \text { TOF }_{d}=\left(e_{1}+e_{2}\right)(1 / V w-1 / V c)
\end{gathered}
$$

where $e_{1}$ and $e_{2}$ are the thicknesses of the anterior and posterior cortices. $\triangle T O F_{d}$ is an increasing function of the cortical thickness. Accordingly, an upper bound for $\triangle T O F_{d}$ is obtained for a thick cortex value. To compute this upper bound, thickness values in the upper range of those usually measured were used: $e_{1}=e_{2}=3 \mathrm{~mm}$. If this leads to an upper bound of $2.5 \mu \mathrm{s}$, then $\Delta$ TOF $_{d}$ is expected to be lower than $2.5 \mu \mathrm{s}$. For the measured TOF at positions $\mathrm{P} 1$ to $\mathrm{P} 9, \triangle T O F=\mathrm{TOF}_{w}-\mathrm{TOF}$ was calculated. A value of $\triangle T O F$ larger than $2.5 \mu \mathrm{s}$ is a strong indication that the measured signal is not the direct wave but a wave that has 
propagated between emitter and receiver significantly faster than the direct wave; ie, with a circumferential wave path in the cortical shell as shown in Fig. 2C. Note that although the path length is longer for the circumferential propagation than for the direct wave, the wave guided in the cortical shell can still arrive earlier because it propagates at the much higher speed of sound in cortical bone than the direct wave does in marrow.

The distribution of each variable was tested for normality using a Lilliefors test. A two-way analysis of variance (ANOVA) was conducted to compare between-specimen variability (differences between specimens) to within-specimen variability (different measurements of a same specimen) of TOF; values were computed for Fisher's $F$ and significance $p$ associated with: ${ }^{(1)}$ the variability due to the different TOF measurements; and ${ }^{(2)}$ the variability due to the different femurs. Univariate correlations between all variables were computed (Pearson's coefficient, $r$ ). Specifically, the relationships between $T O F_{m}$ on one hand, and QCT and mechanical variables on the other hand were examined. The possible added value of combining different measurements performed with different techniques (QUS, DXA, QCT) to predict $F_{\text {max }}$, was investigated with a stepwise regression including all the explaining variables for which the univariate correlation with $F_{\text {max }}$ were significant. For all analyses, $p$ values smaller than 0.05 were considered significant. Statistical analyses were conducted using MATLAB statistics toolbox (MATLAB; The Mathworks, Natick, MA, USA).

\section{Results}

The normal distribution hypothesis was not rejected for the QUS, QCT, DXA, and mechanical datasets.

The variability of TOF for all the specimens, at the measurement positions $\mathrm{P} 1$ to $\mathrm{P9}$, is shown in Fig. 3. For all specimens and all positions P1 to P9, $\Delta$ TOF was between $5.5 \mu \mathrm{s}$ and $10.8 \mu \mathrm{s}$, which is larger than the estimated upper bound for $\Delta \operatorname{TOF}_{d}(2.5 \mu \mathrm{s})$ associated with the direct wave. This means that

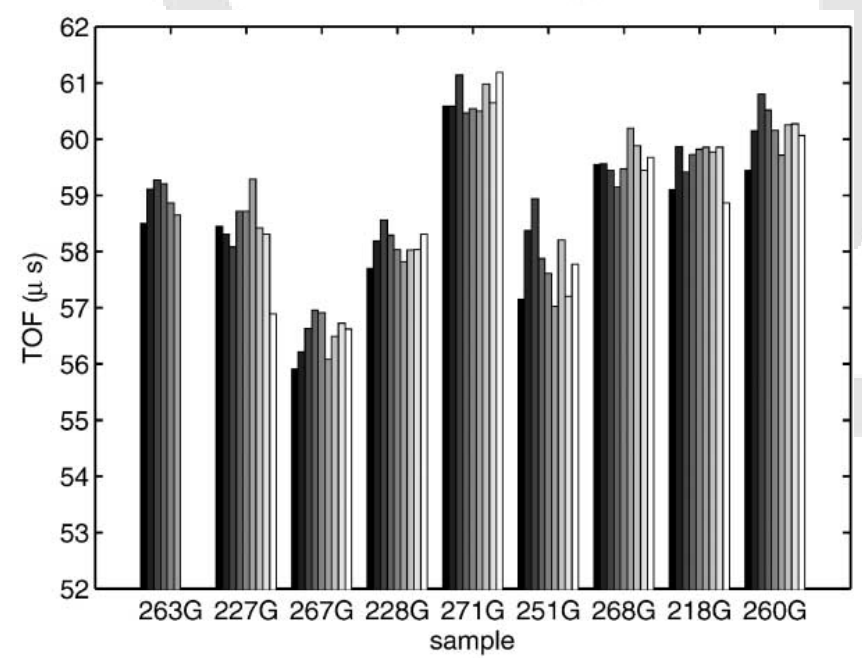

Fig. 3. Summary of TOF values at measurement positions P1-P9 (from left to right), for each specimen. The reference TOF in water was about $66.7 \mu \mathrm{s}$. the FAS is arriving much earlier than the direct wave and corresponds to a wave guided in the cortex (Fig. 2C).

Two-way ANOVA showed that the within-specimen variability $(F=1.7, p=0.13)$ was negligible compared to the betweenvariability $\left(F=102.6, p<1 \times 10^{-6}\right)$. Note that one specimen (\#263G) was excluded from the ANOVA because it could only be measured on six positions instead of nine due to technical problems unrelated to the measurement protocol. For further data analysis, only the average TOF $_{m}$ was considered for each specimen.

Descriptive statistics are given in Table 1 and intercorrelations $^{\mathrm{Q7}}$ in Table 2, where univariate correlations with $\mathrm{TOF}_{m}$ are highlighted because they are the principal results of the study. Among QCT variables, TOF $_{m}$ only significantly correlated: ${ }^{(1)}$ with volumetric $B M D$ averaged over the whole cortical compartment (BMDCortAll, $R^{2}=0.54$ ) and in the anterior quadrants (BMDCortIA, $R^{2}=0.90$, Fig. 4; BMDCortSA, $\left.R^{2}=0.57\right)$; and ${ }^{(2)}$ with the moment of inertia (AMIMCortall, $R^{2}=0.71$ ). There was no significant correlation between $T O F_{m}$ and cortical thickness. DXA variables explained 59\% (NeckBMDDXA) and 67\% (TBMDDXA) of TOF respectively. For all the specimens, the mechanical loading led to a fracture of the neck (no trochanteric fracture occurred).

Table 1. Mean, SD, and Range of the Measured Quantities: QUS Variables, QCT Variables, and DXA Variables

\begin{tabular}{lccc}
\hline & Mean & SD & Range \\
\hline QUS variables & & & \\
TOF $m(\mu \mathrm{s})$ & 58.86 & 1.3 & $56.50-60.74$ \\
$F_{\text {max }}(\mathrm{N})$ & 5815 & 1926 & $3695-10249$ \\
QCT variables & & & \\
BMDCortAll $\left(\mathrm{mg} / \mathrm{cm}^{3}\right)$ & 515.29 & 127.24 & $349.79-677.62$ \\
BMDCortSA $\left(\mathrm{mg} / \mathrm{cm}^{3}\right)$ & 330.60 & 101.33 & $189.00-452.24$ \\
BMDCortIA $\left(\mathrm{mg} / \mathrm{cm}^{3}\right)$ & 616.97 & 146.45 & $415.58-820.67$ \\
BMDCortSP $\left(\mathrm{mg} / \mathrm{cm}^{3}\right)$ & 289.06 & 130.14 & $84.83-487.99$ \\
BMDCortIP $\left(\mathrm{mg} / \mathrm{cm}^{3}\right)$ & 728.11 & 160.62 & $399.43-930.85$ \\
ThickCortIA $(\mathrm{mm})$ & 2.55 & 0.25 & $2.15-3.04$ \\
ThickCortIP $(\mathrm{mm})$ & 2.63 & 0.36 & $2.08-3.35$ \\
VolCortAIl $\left.(\mathrm{mm})^{3}\right)$ & 5.15 & 1.09 & $2.97-6.33$ \\
AMIMCortAll $\left(\mathrm{g} . \mathrm{cm}^{2}\right)$ & 6.70 & 3.05 & $2.20-12.17$ \\
DXA variables & & & \\
TBMDDXA $\left(\mathrm{g} / \mathrm{cm}^{2}\right)$ & 0.62 & 0.16 & $0.32-0.87$ \\
NeckBMDDXA $\left(\mathrm{g} / \mathrm{cm}^{2}\right)$ & 0.50 & 0.13 & $0.25-0.64$ \\
\hline
\end{tabular}

QUS = quantitative ultrasound; $T O F_{m}=$ average time-of-flight; $F_{\max }=$ strength; $\mathrm{QCT}=$ quantitative computed tomography; $\mathrm{DXA}=$ dual-energy $\mathrm{X}$-ray absorptiometry; $\mathrm{BMD}=$ bone mineral density; $\mathrm{FN}=$ femoral neck; $B M D C o r t A l l=$ volumetric $B M D$ averaged over the entire $\mathrm{FN}$ cortical compartment; $B M D C o r t S A=$ volumetric BMD of the FN cortical compartment in the superoanterior quadrant; $B M D C o r t S P=$ volumetric $B M D$ of the FN cortical compartment in the superoposterior quadrant; $B M D C$ ort $/ A=$ volumetric $B M D$ of the $\mathrm{FN}$ cortical compartment in the inferoanterior quadrant; $B M D C$ ort $I P=$ volumetric $B M D$ of the $\mathrm{FN}$ cortical compartment in the inferoposterior quadrant; ThickCort/A=average cortical bone thickness in the inferoanterior quadrant; ThickCortIP= average cortical bone thickness in the inferoposterior quadrant; VolCortAll=volume of the entire FN cortical compartment; AMIMCortAll = density-weighted areal moment of inertia of the FN cortical compartment; TBMDDXA = areal BMD for the total proximal femur; $N e c k B M D D X A=$ areal $B M D$ for the neck region. 


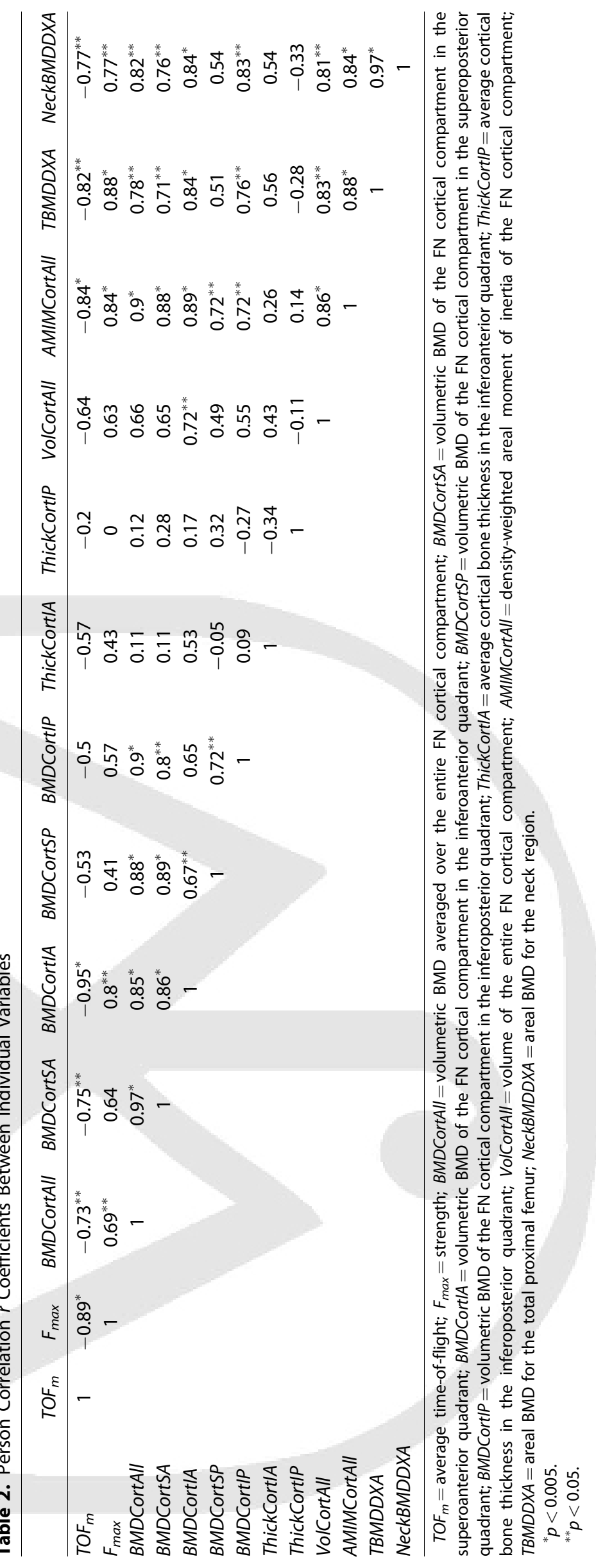




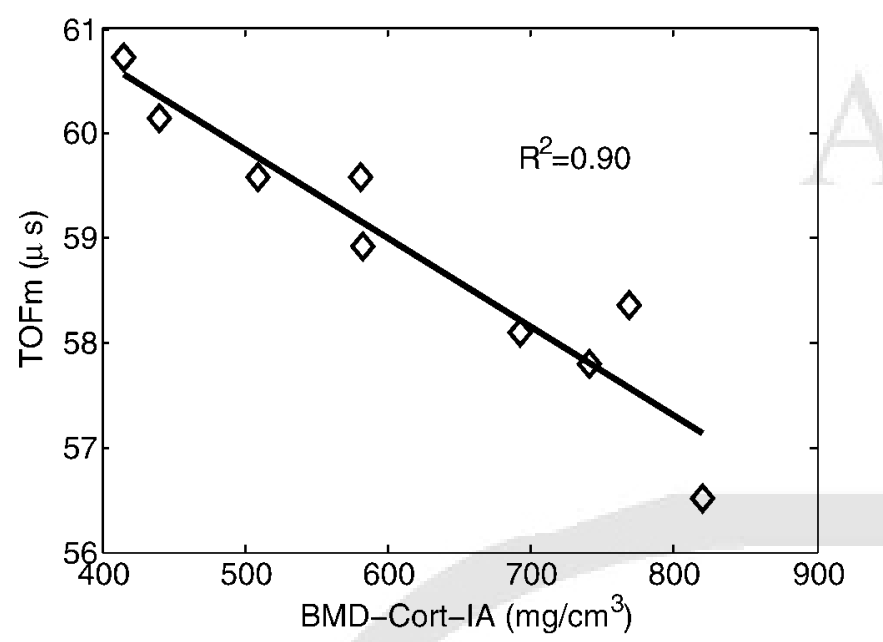

Fig. 4. Time-of-flight $\left(T O F_{m}\right)$ versus cortical volumetric $B M D$ in the inferoanterior (BMDCortIA) quadrant.

Cortical ultrasound measurement $\left(\right.$ TOF $\left._{m}\right)$ explained $79 \%$ of the failure load $\left(F_{\text {max }}\right)$ variance (Fig. 5). Note that even after removing the rightmost point $\left(F_{\text {max }}\right.$ around $\left.10 \mathrm{kN}\right)$ on Fig. 5, the correlation is still high and significant $\left(R^{2}=0.69 ; p=0.01\right)$. After adjustment for bone size (cross-sectional area), the TOF $_{m}$ explained $86 \%$ of $F_{\text {max }}$ and DXA variables explained 60\% (NeckBMDDXA) and $78 \%$ (TBMDDXA) of the failure load variance. QCT variables for which the correlation with $F_{\text {max }}$ was significant were BMDCortAll $\left(R^{2}=48\right), B M D C o r t I A\left(R^{2}=64\right)$, and moment of inertia (AMIMCortAll, $\left.R^{2}=71\right)$.

The stepwise regression yielded a model with only $T O F_{m}$ as a significant explaining variable of $F_{\max }$. This result should be balanced by the fact that the study only involved a small number of specimens.

\section{Discussion}

In this ex vivo study the feasibility of QUS measurement of the cortical bone compartment at the FN was established. Nine femurs were subjected to QUS, QCT, and DXA measurements, and mechanical tests. On one hand, the ultrasound TOF was

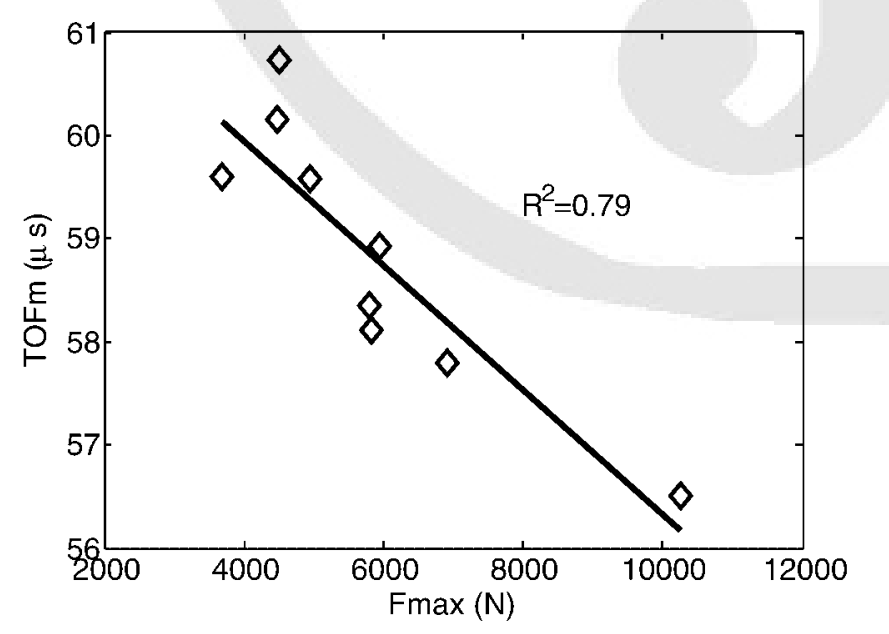

Fig. 5. Time-of-flight $\left(T O F_{m}\right)$ versus strength $\left(F_{\max }\right)$. found to be highly sensitive to properties of the IA cortical part of the neck, as evidenced by the strong correlation of $T O F_{m}$ and volumetric BMD in the IA quadrant. On the other hand, TOF $m$ was strongly correlated to femur strength, indicating the ability of QUS to probe critical determinants of bone strength in the cortical compartment of the FN.

QUS measurements of the proximal femur have been recently reported using a prototype clinical device and have been shown to efficiently predict fracture risk. ${ }^{(22)}$ The prototype scanner uses spherically focused transducers moving in a $2 \mathrm{D}$ scan to achieve an image of QUS variables (attenuation and speed of sound) at the proximal femur. With this approach, different regions can be measured, such as the great trochanter, the shaft, or the surrounding soft tissue. In their study, the authors depicted signals that were interpreted as arising from a guided wave transmitted in the cortex of the shaft below the minor trochanter or even in the inferior part of the neck. However, an analysis to support this interpretation was lacking. In the present study, an analysis was done of ultrasound propagation in the FN, a very relevant fracture site for hip fractures. A thorough analysis and comparison of the arrival time of the FAS with the upper bound of the arrival time of the direct wave supports a propagation guided circumferentially along the cortical shell. Furthermore, this is consistent with previous model predictions. ${ }^{(25)}$

An interesting finding of this study was the strong correlation of $T_{O F}$ with $B M D C o r t I A$, which was much stronger than with $\mathrm{BMD}$ in other quadrants. This leads to the question of which part of the femur neck is actually probed by our ultrasound approach. The circumferential guided propagation can follow two directions, upward and downward (Fig. 2C). The contribution to the TOF may thus arise from either direction, which is not equivalent because FN displays a strong asymmetry, the superior part being much thinner than the inferior part that carries most of the load during walking. ${ }^{(39)}$ The TOF measured is likely that of waves that have propagated in the lower part of the neck. This assertion is consistent with results of numerical simulations of our ultrasound experiment. Simulations were conducted, following the method described in Grondin and colleagues, ${ }^{(25)}$ for three typical FN cross-sectional shapes with different thickness in the inferior quadrants (Fig. 6). The simulated wavefields clearly show that the wavefronts of circumferential waves are in advance of the direct wave front. The large thickness in the inferior part favors high propagation velocities. The upward and downward circumferential waves propagate along similar distances; hence, the signal retrieved at the receiver is associated to the fastest wave, eg, the downward circumferential wave. This wave path is consistent with the strong correlation between $T O F_{m}$ and BMDCortIA.

It is remarkable that the proposed ultrasound method is particularly sensitive to the variations of BMD in the anterior and inferior neck region because there is evidence that this cortical region is particularly subject to remodeling and consequently may undergo large variations in its properties, particularly in porosity. Bousson and colleagues ${ }^{(40)}$ found porosity values in the inferior cortex varying from $4.96 \%$ to $38.87 \%$ (mean, $15.88 \% \pm 9.87 \%$ ). Several studies pointed that the cortical bone properties in the neck, and in particular in the anterior and inferior regions, were different in fracture cases and postmortem 


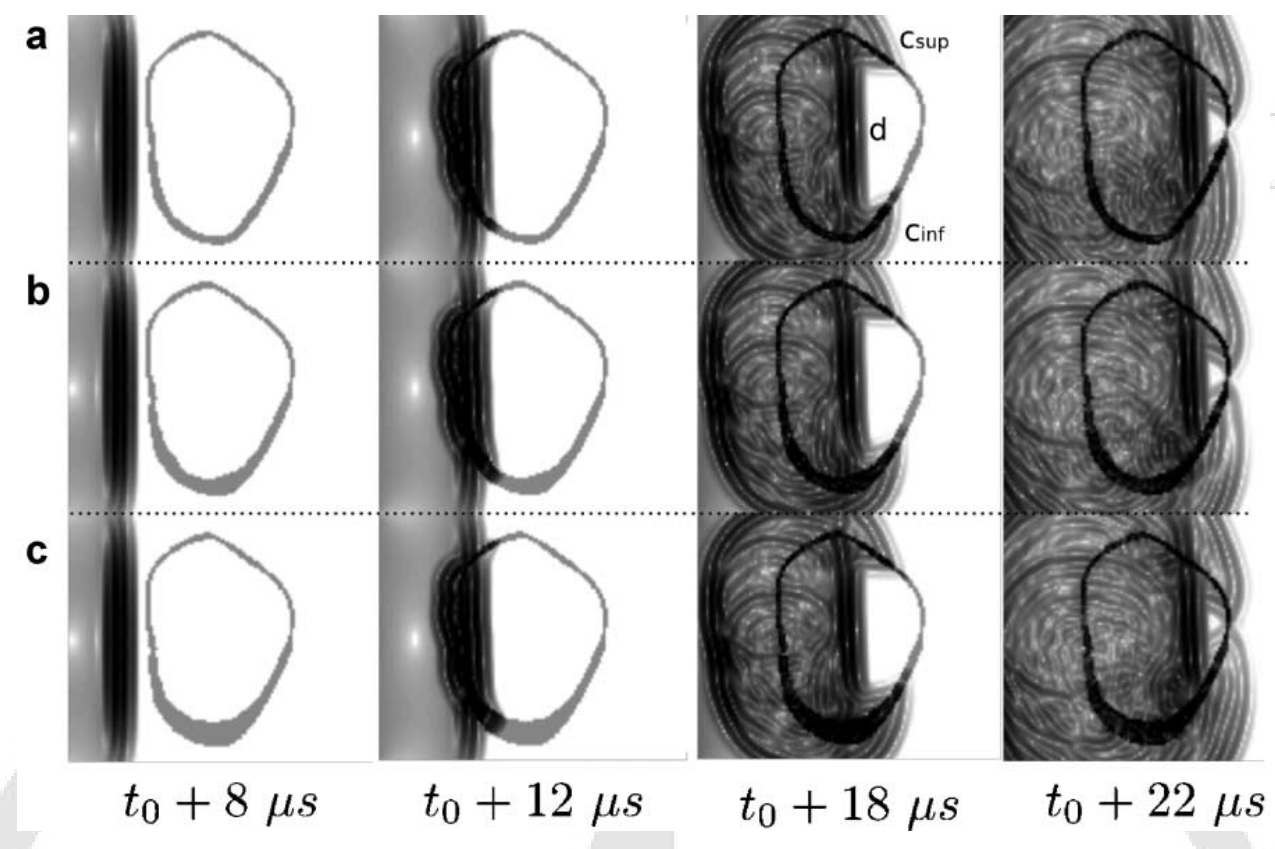

Fig. 6. Simulations of ultrasound wave propagation in three cross-sections of FN (trabecular bone not represented). Images of the simulated wave field are given at four time steps $\left(8,12,18\right.$, and $22 \mu \mathrm{s}$ after the time reference $t_{0}$, from left to right). The circumferential waves in the cortical shell ( $C_{\text {inf }}$ and $C_{\text {sup }}$ in the inferior and superior parts, respectively) are seen in advance of the direct wave front (d). Cross-sectional shapes were drawn after an image ${ }^{(29)}(B)$ and the inferior thickness was artificially decreased $(A)$ or increased $(C)$. The circumferential wave front propagates faster in the thick inferior cortex than in the thin superior cortex.

controls. Bell and colleagues ${ }^{(31)}$ found that porosity in the anterior cortex of the fracture group was $41 \%$ higher than in controls. These changes in porosity are associated with increased indices of Haversian remodeling ${ }^{(41)}$ and with the formation of "giant canals," the proportion of which was found to be larger in the anterior quadrant. ${ }^{(31,42)}$ At the FN between fracture cases and postmortem controls, Loveridge and Reeve ${ }^{(43)}$ showed differences in mineralization, and Loveridge and colleagues ${ }^{(44)}$ showed differences in mineralized matrix hardness. Fracture cases had a lower mineralization level, particularly in the inferior quadrants $(-3.3 \%)$, and lower hardness in the inferior $(-2.5 \%)$ and anterior $(-3.9 \%)$ regions. Such variations, which are critically indicative of cortical bone status, are likely to be captured by a measurement configuration that specifically favors the propagation in the lower region of the neck cortex.

Considering the circumferential propagation involved in the measurements, TOF decreases when the wave speed increases but increases with the size of the circumference. The size and the shape of the bone are thus a priori important determinants of TOF. These relationships between TOF and bone size and shape can partially explain the correlation found between the moment of inertia (AMIMCortAll) and $T_{O} F_{m}\left(R^{2}=0.71\right)$. However, data interpretation is complicated by the fact that the parameters are not all independent. In particular, BMD and the moments of inertia are correlated. For example, BMDCortIA explains $68 \%$ of the variability of moments of inertia. The consequence of these correlations and the small sample size studied here makes it difficult to determine the true contribution of the bone geometrical variability to the TOF variability, independently from BMD. The relative contributions of bone size, shape, and material properties to the TOF can be best explored in experimental studies conducted on a much larger sample size. The impact of bone geometrical variability on TOF can also be documented using numerical simulations of wave propagation in a configuration similar to the experiments. Numerical simulations in which all the FNs had the same material properties but individualized geometry reconstructed from CT scan data sets had been previously conducted. It had previously been found that the minimum moment of inertia of the mid-neck crosssection is an important independent predictor of the TOF $\left(R^{2}=72\right){ }^{(25)}$

TOF is in part determined by the wave speed, which in turn depends on the material properties of the waveguide. In our setup, the wavelength of ultrasound in the cortical bone is about $8 \mathrm{~mm}$. Accordingly, the ultrasound circumferential guided wave probes' effective material properties (apparent density and apparent elasticity) were averaged over one wavelength, not only over the cortical thickness but also in the circumferential direction. These effective properties strongly depend on cortical porosity. ${ }^{(45)}$

The dependence of the speed of sound on cortical thickness in addition to the dependence on material properties is specific to wave propagation in waveguides. ${ }^{(46)}$ However, no significant correlation between TOF and the cortical thickness of the inferior quadrants was found. There may be several reasons for this: ${ }^{(1)}$ there is only a $10 \%$ to $15 \%$ variability in cortical thickness compared to the $25 \%$ variability of the BMD in the IA quadrant; and ${ }^{(2)}$ between-specimen variability of ThickCortlA and ThickCortIP is around $300 \mu \mathrm{m}$, which is very close to the resolution of the $C T$ scans. Hence, the variability and the precision of thickness estimates may be insufficient, making it difficult to observe any correlation between TOF and cortical 
thickness. High-resolution $\mathrm{CT}$ scans should be performed in future studies to clarify the relationships between TOF and cortical thickness.

TOF is thus potentially an interesting parameter because it captures a wealth of information, including material, geometrical, and structural characteristics, that pertains to strength. Further characterization of cortical bone at the neck, independently from its geometrical features, might be of interest to provide an estimate of the cortical status. Such a characterization would require deriving the wave speed from TOF measurements. To achieve this goal, the length of the pathway must be known. Combining QUS-based measurements of TOF with X-ray-based measurements of bone geometry might be a solution. Low-dose CT might be sufficient for this purpose, but increased examination cost and time of such a multimodality approach have to be balanced against the increase in predictive power for fracture risk.

In this work, for the first time, a comparison between QUS of FN cortical bone and FN strength is presented. TOF and strength were found to be strongly related $\left(R^{2}=0.79\right)$. In fact, the relationship between TOF and strength are mediated by the above mentioned causal relationships that exist between TOF and the propagation path length (ie, bone size and shape) and guided wave speed (ie, material properties such as mass, density, stiffness, and porosity). Although a clear relationship between TOF and cortical thickness in this study could not be shown, the fact that our QUS modality involves guided waves, the speed of which are influenced by the thickness of the wave guide, is potentially clinically significant considering, eg, the results reported by Crabtree and colleagues, ${ }^{(32)}$ who found that the mean cortical width in fracture cases was significantly lower in the IA (22.2\%; $p=0.002)$ and inferior regions (18.8\%; $p<0.001)$.

The QUS modality used in this study probes cortical bone only and is not sensitive to the properties of the trabecular compartment, as shown by a recent simulation study by our group (data not shown). The high correlation between TOF and strength suggests that cortical bone determines a large part of bone strength assessed in a one-leg-stance mechanical test configuration. This has already been pointed out in several publications. ${ }^{(10-13)}$ With the cylindrically focused transducers used here, the whole FN cross-section is sonicated in a single shot that allows a simple and fast measurement of the cortical compartment without the need for scanning the ultrasound beam through the neck. A simple, time-based discrimination on the signal allows extraction of the component associated with the guided propagation in the cortical shell. The downside counterpart of line focusing is the absence of an image. However, technical solutions exist, such as arrays of transducers, to combine fast 2D scanning with line focusing in a single apparatus. Such a technical approach would also permit a combined assessment of both trabecular and cortical compartments.

In this study on nine specimens, the correlations between QUS and DXA with strength were found to be very similar: $R^{2}=79 \%$ for QUS, $R^{2}=78 \%$ for DXA (total proximal femur). Both cortical and trabecular bone compartments contribute to the DXA values, which correspond to an average of a $2 \mathrm{D}$ projectional measurement of BMD. It is remarkable that the QUS measure- ment performs as well as DXA by solely probing the cortical compartment. As mentioned above, several studies have pointed out the important contribution of cortical bone to strength.

This study has several limitations. Although a limited set of specimens $(n=9)$ was studied, the distribution of the mechanical, QCT, and DXA values, compared to those found in comparable studies, are well within the range of reported values. Nevertheless, the results need to be tested in a larger independent set of specimens. This study only investigated a one-legged-stance configuration that exclusively leads to cervical fractures, as expected. This choice was constitutive of the present study because the interest was in FN, and not trochanteric, properties. Mechanical tests simulating fracture after a fall on the trochanter would have led to various fracture types, ${ }^{(47)}$ which may not be as well related to the type of QUS measurement presented in this work. In particular, trabecular bone may be more important for strength in regard to trochanteric fractures, ${ }^{(48)}$ but it has been shown that other QUS measurement modes also allow the assessment of this type of fracture risk. ${ }^{(22)}$ Another limitation, the spatial resolution of QCT scans (in-plane pixel size of about $200 \mu \mathrm{m}$ ), may have led to an underestimation of the respective correlations with TOF.

The question arises regarding the in vivo applicability of the method to measure the cortical part of the FN. In a pilot clinical study, Barkmann and colleagues ${ }^{(22)}$ demonstrated that femur QUS is feasible and shows a good performance for hip fracture discrimination. Signals from waves propagating preferentially in the inferior part of the neck cortex could be observed but were not actually used for the discrimination of fracture cases because for some subjects the FN signal amplitude was too low. These results with the first hip QUS scanner reinforce our idea that measurement of the inferior cortex could be performed in vivo. Optimal positioning of the ultrasound beam with respect to the FN could be achieved automatically using an ultrasound imaging modality and selection of region of interest following Barkmann and colleagues. ${ }^{(22)}$ The approach developed in our ex vivo study was designed to favor the transmission and fast measurement of a wave guided circumferentially in the neck cortex. A specific measurement protocol and signal processing was adopted to reach robust estimates of TOF with respect to small uncertainties in transducer positioning. Such a protocol, basically consisting of multiple measurements performed at different positions and angles, which represent small deviations from a reference position at the center of the neck, and averaging TOF for the different positions, is suitable for an in vivo implementation. Although it was previously shown that ultrasound can measure the hip, ${ }^{(22)}$ the in vivo performance of our approach will not be clear, however, until a range of experimental data has been analyzed in patients for challenging conditions; eg, signal-tonoise ratio, intervening soft tissue, transducer positioning, and measurement precision. Further improvements of the method include ${ }^{(1)}$ differential measurement of the lower and upper neck cortex, the latter being also critical regarding neck stability, which can be achieved by focusing the beam specifically on the corresponding part of the neck to be measured; ${ }^{(2)}$ separate assessment of the geometry and material properties of the neck with advanced signal processing to measure both TOF and 
wave speed $^{(35)}$; and ${ }^{(3)}$ combining QUS modalities to probe both the trabecular and cortical compartments.

\section{Conclusion}

In this ex vivo study it was shown that QUS measurements favoring the propagation and the measurement of a wave propagating circumferentially in the cortical shell of the FN were strongly correlated with femoral bone strength. More specifically, TOF was found to be highly sensitive to the variations of regional cortical bone properties in the inferoanterior cortex. This supports the notion that TOF reflects a combination of cortical tissue elastic properties-which are in turn affected by mineralization and porosity - and geometrical properties, all of them known to be relevant for femoral neck strength. Specifically, this study has shown the relevance of measuring the FN cortical shell with ultrasound. Following the findings in this work, novel hip QUS systems for clinical assessment could be devised to complement the assessment of the trabecular compartment with assessment of the cortical compartment for the benefit of enhanced risk prediction and monitoring of drug-induced changes in bone properties. It is also possible that combining X-ray and ultrasound measurements would provide better indicators of bone quality. Although the methodology for assessing bone using ultrasound is much less developed to date than using X-rays, the potential of ultrasound extends far beyond the currently available QUS techniques and is largely unexploited. Ultrasound waves are intrinsically suited to probe mechanical properties, and have the best chance to noninvasively yield an improved estimation of bone fragility combined with advantages such as lack of ionizing radiation and cost-effectiveness.

\section{Disclosures}

All authors state that they have no conflicts of interest.

\section{Acknowledgments}

This work has been conducted within the European Associated Laboratory "Ultrasound Based Assessment of Bone" (ULAB), a cooperation of centers in Paris (France) and Kiel and Berlin (Germany), funded by CNRS (France). We thank Daniel Rohrbach for providing the 3D representation of the QUS experiment and Hendrick de Graaf for his contribution to the statistical analysis.

Authors' roles: Study design: QG, JG, and PL. Data acquisition and processing: JG, RB, SG, QG, and KE. Statistical analysis: JG, QG, and PL. Data interpretation: QG, JG, SG, RB, KE, CCG, and PL. Drafting manuscript: QG, JG, and PL. Revising manuscript content: QG, JG, SG, RB, KE, CCG, and PL. Approval final version of manuscript QG, JG, SG, RB, KE, CCG, and PL. QG takes responsibility for the integrity of the data analyses.

\section{References}

1. Keene GS, Parker MJ, Pryor GA. Mortality and morbidity after hip fractures. BMJ. 1993;307(6914):1248-50.

2. Cummings SR, Melton LJ. Epidemiology and outcomes of osteoporotic fractures. Lancet. 2002;359(9319):1761-7.
3. Marshall D, Johnell O, Wedel H. Meta-analysis of how well measures of bone mineral density predict occurrence of osteoporotic fractures. BMJ. 1996;312(7041):1254-9.

4. Stone KL, Seeley DG, Lui LY, Cauley JA, Ensrud K, Browner WS, Nevitt MC, Cummings SR. Osteoporotic Fractures Research Group. BMD at multiple sites and risk of fracture of multiple types: long-term results from the study of osteoporotic fractures. J Bone Miner Res. 2003;18(11):1947-54.

5. Siris ES, Chen YT, Abbott TA, Barrett-Connor E, Miller PD, Wehren LE, Berger ML. Bone mineral density thresholds for pharmacological intervention to prevent fractures. Arch Intern Med. 2004;164(10): 1108-12.

6. Wilkin TJ, Devendra D. Bone densitometry is not a good predictor of hip fracture. BMJ. 2001;323(7316):795-7.

7. Delmas PD, Seeman E. Changes in bone mineral density explain little of the reduction in vertebral or nonvertebral fracture risk with antiresorptive therapy. Bone. 2004;34(4):599-604.

8. Gallacher SJ, Dixon T. Impact of treatments for postmenopausal osteoporosis (bisphosphonates, parathyroid hormone, strontium ranelate, and denosumab) on bone quality: a systematic review. Calcif Tissue Int. 2010;87(6):469-84.

9. Pulkkinen P, Glüer CC, Jämsä T. Investigation of differences between hip fracture types: a worthy strategy for improved risk assessment and fracture prevention. Bone. 2011;49(4):600-4.

10. Bousson V, Le Bras A, Roqueplan F, Kang Y, Mitton D, Kolta $S$, Bergot C, Skalli W, Vicaut E, Kalender W, Engelke K, Laredo JD. Volumetric quantitative computed tomography of the proximal femur: relationships linking geometric and densitometric variables to bone strength role for compact bone. Osteoporos Int. 2006;17(6): 855-64.

11. Holzer G, Skrbensky G, Holzer LA, Pichl W. Hip fractures and the contribution of cortical versus trabecular bone to femoral neck strength. J Bone Miner Res. 2009;24(3):468-74.

12. Mayhew PM, Thomas CD, Clement JG, Loveridge N, Beck TJ, Bonfield W, Burgoyne CJ, Reeve J. Relation between age, femoral neck cortical stability, and hip fracture risk. Lancet. 2005;366(9480):129-35.

13. Turner $\mathrm{CH}$. The biomechanics of hip fracture. Lancet. 2005; 366(9480):98-9.

14. Lotz JC, Cheal EJ, Hayes WC. Stress distributions within the proximal femur during gait and falls: implications for osteoporotic fracture. Osteoporos Int. 1995;5(4):252-61.

15. Atkinson PJ. Quantitative analysis of osteoporosis in cortical bone. Nature. 1964;201:373-5.

16. Zebaze RMD, Ghasem-Zadeh A, Bohte A, luliano-Burns S, Mirams M, Price RI, Mackie EJ, Seeman E. Intracortical remodelling and porosity in the distal radius and post-mortem femurs of women: a crosssectional study. Lancet. 2010;375(9727):1729-36.

17. Damilakis J, Adams JE, Guglielmi G, Link TM. Radiation exposure in Xray-based imaging techniques used in osteoporosis. Eur Radiol. 2010;20(11):2707-14.

18. Prevrhal S, Engelke $K$, Kalender WA. Accuracy limits for the determination of cortical width and density: the influence of object size and ct imaging parameters. Phys Med Biol. 1999;44(3):751-64.

19. Prevrhal S, Fox JC, Shepherd JA, Genant HK. Accuracy of ct-based thickness measurement of thin structures: modeling of limited spatial resolution in all three dimensions. Med Phys. 2003;30(1):1-8.

20. Black DM, Bouxsein ML, Marshall LM, Cummings SR, Lang TF, Cauley $J A$, Ensrud KE, Nielson CM, Orwoll ES. Osteoporotic Fractures in Men (MrOS) Research Group. Proximal femoral structure and the prediction of hip fracture in men: a large prospective study using QCT. J Bone Miner Res. 2008;23(8):1326-33.

21. Bousson VD, Adams J, Engelke K, Aout M, Cohen-Solal M, Bergot $C$, Haguenauer D, Goldberg D, Champion K, Aksouh R, Vicaut E, Laredo JD. In vivo discrimination of hip fracture with quantitative computed 
tomography: results from the prospective European femur fracture study (EFFECT). J Bone Miner Res. 2011;26(4):881-93.

22. Barkmann R, Dencks S, Laugier P, Padilla F, Brixen K, Ryg J, Seekamp A, Mahlke L, Bremer A, Heller M, Glüer CC. Femur ultrasound (FemUS)first clinical results on hip fracture discrimination and estimation of femoral BMD. Osteoporos Int. 2010;21(6):969-76.

23. Barkmann R, Laugier $P$, Moser U, Dencks $S$, Klausner M, Padilla F, Haiat $\mathrm{G}$, Heller M, Gluer CC. In vivo measurements of ultrasound transmission through the human proximal femur. Ultrasound Med Biol. 2008;34(7):1186-90.

24. Barkmann R, Lusse S, Stampa B, Sakata S, Heller M, Gluer CC. Assessment of the geometry of human finger phalanges using quantitative ultrasound in vivo. Osteoporos Int. 2000;11(9):745-55.

25. Grondin J, Grimal Q, Engelke K, Laugier P. Potential of first arriving signal to assess cortical bone geometry at the hip with QUS: a model based study. Ultrasound Med Biol. 2010;36(4):656-66.

26. Rohrbach D, Grondin J, Grimal Q, Laugier P, Barkmann R, Raum K. Evidence based numerical ultrasound simulations at the human femoral neck. Biomed Tech (Berl). 2010; 55 Suppl1.

27. Laugier $P$, Haïat $G$, editors. Bone quantitative ultrasound. New York: Springer; 2010.

28. Le Floch V, Luo G, Kaufman JJ, Siffert RS. Ultrasonic assessment of the radius in vitro. Ultrasound Med Biol. 2008;34(12):1972-9.

29. Loveridge N, Power J, Reeve J, Boyde A. Bone mineralization density and femoral neck fragility. Bone. 2004;35(4):929-41.

30. Fratzl-Zelman N, Roschger P, Gourrier A, Weber M, Misof BM, Loveridge N, Reeve J, Klaushofer K, Fratzl P. Combination of nanoindentation and quantitative backscattered electron imaging revealed altered bone material properties associated with femoral neck fragility. Calcif Tissue Int. 2009;85(4):335-43.

31. Bell KL, Loveridge N, Power J, Garrahan N, Meggitt BF, Reeve J. Regional differences in cortical porosity in the fractured femoral neck. Bone. 1999;24(1):57-64.

32. Crabtree N, Loveridge N, Parker M, Rushton N, Power J, Bell KL, Beck $\mathrm{TJ}$, Reeve J. Intracapsular hip fracture and the region-specific loss of cortical bone: analysis by peripheral quantitative computed tomography. J Bone Miner Res. 2001;16(7):1318-28.

33. Power J, Loveridge N, Lyon A, Rushton N, Parker M, Reeve J. Bone remodeling at the endocortical surface of the human femoral neck: a mechanism for regional cortical thinning in cases of hip fracture. J Bone Miner Res. 2003;18(10):1775-80.

34. Barkmann R, Dencks S, Bremer A, Laugier P, Padilla F, Brixen K, Ryg J, Gluer CC. Femur ultrasound (FemUS) - a new method for the estimation of osteoporotic fracture risk?. Calcif Tissue Int. 2008; 82:S166-7.
35. Nauleau P, Cochard E, Minonzio JG, Grimal Q, Laugier P, Prada C. Characterization of circumferential guided waves in a cortical bonemimicking cylindrical phantom. J Acoust Soc Am. 2012 Apr; 131(4): EL289-94.

36. Kang $Y$, Engelke $K$, Kalender WA. A new accurate and precise 3-D segmentation method for skeletal structures in volumetric ct data. IEEE Trans Med Imaging. 2003;22(5):586-98.

37. Kang $Y$, Engelke $K$, Fuchs $C$, Kalender WA. An anatomic coordinate system of the femoral neck for highly reproducible BMD measurements using 3D QCT. Comput Med Imaging Graph. 2005;29(7): 533-41.

38. Kubo T, Fujimori K, Cazier N, Saeki T, Matsukawa M. Properties of ultrasonic waves in bovine bone marrow. Ultrasound Med Biol. 2011;37(11):1923-9.

39. Lovejoy CO. Evolution of human walking. Sci Am. 1988;259(5): 118-25.

40. Bousson V, Peyrin F, Bergot C, Hausard M, Sautet A, Laredo JD. Cortical bone in the human femoral neck: three-dimensional appearance and porosity using synchrotron radiation. J Bone Miner Res. 2004;19(5):794-801.

41. Bell KL, Loveridge N, Power J, Rushton N, Reeve J. Intracapsular hip fracture: increased cortical remodeling in the thinned and porous anterior region of the femoral neck. Osteoporos Int. 1999;10(3): 248-57.

42. Jordan GR, Loveridge N, Bell KL, Power J, Rushton N, Reeve J. Spatial clustering of remodeling osteons in the femoral neck cortex: a cause of weakness in hip fracture?. Bone. 2000;26(3): 305-13.

43. Loveridge $\mathrm{N}$, Reeve J. Femoral neck fragility: genes or environment?. J Musculoskelet Neuronal Interact. 2004;4(2):148-51.

44. Loveridge N, Follon E, Power J, Reeve J, Bonfield W. Decreased bone hardness in hip fracture: regional changes and the association with bone remodelling. Bone. 2003;33:S1-29.

45. Granke M, Grimal Q, Saïed A, Nauleau P, Peyrin F, Laugier P. Change in porosity is the major determinant of the variation of cortical bone elasticity at the millimeter scale in aged women. Bone. 2011;49(5): 1020-6.

46. Talmant M, Foiret J, Minonzio JG., Guided waves in cortical bone. In: Laugier P, Haïat G, editors. Bone quantitative ultrasound. New York Springer 2011. 147-180.

47. Keyak JH Relationships between femoral fracture loads for two load configurations J Biomech 2000;33(4) 499-502

48. Mautalen CA, Vega EM, Einhorn TA., Are the etiologies of cervical and trochanteric hip fractures different? Bone. 1996;18(3 Suppl): 133S-7S. 


\section{JOURNAL: JOURNAL OF BONE AND MINERAL RESEARCH Article: jbmr_1742}

Dear Author,

During the copyediting of your paper, the following queries arose. Please respond to these by annotating your proofs with the necessary changes/additions.

- If you intend to annotate your proof electronically, please refer to the E-annotation guidelines.

- If you intend to annotate your proof by means of hard-copy mark-up, please refer to the proof mark-up symbols guidelines. If manually writing corrections on your proof and returning it as a scanned pdf via email, do not write too close to the edge of the paper. Please remember that illegible mark-ups may delay publication.

Whether you opt for hard-copy or electronic annotation of your proofs, we recommend that you provide additional clarification of answers to queries by entering your answers on the query sheet, in addition to the text mark-up.

\begin{tabular}{|c|l|c|}
\hline Query No. & \multicolumn{1}{|c|}{ Query } & Remark \\
\hline Q1 & $\begin{array}{l}\text { Please verify short title added. If it is not suitable, please provide one of 70 } \\
\text { characters or fewer, including spaces. }\end{array}$ & \\
\hline Q2 & $\begin{array}{l}\text { Please spell out or define all abbreviations in affiliations 1-3. Also, in affiliation 3, } \\
\text { please provide the department and/or division name. }\end{array}$ & \\
\hline Q3 & $\begin{array}{l}\text { Please clarify the meaning of "which TOF was not influenced by the properties } \\
\text { of the trabecular compartment." }\end{array}$ & \\
\hline Q4 & In the legend for Fig. 1, please specify the section heading meant by "(see text)." & \\
\hline Q5 & $\begin{array}{l}\text { Per style, references must be cited in numeric order and all references must be } \\
\text { cited. Here, Ref. 35 is cited before Ref. 34; Ref. 34 is not cited in the text at all. } \\
\text { Please cite Ref. 34 before this point in the text and after the citation for Ref. 33, } \\
\text { or remove Ref. 34 from the references and renumber the remaining references } \\
\text { and their citations. }\end{array}$ & \\
\hline Q6 & $\begin{array}{l}\text { Per style, all variables in the text were italicized, and subvariables (such as " } m \text { " in } \\
\text { TOFm) were standardized to subscripts. Please verify. }\end{array}$ \\
\hline Q7 & $\begin{array}{l}\text { Please verify the abbreviation definitions in the footnotes to Tables 1 and 2. } \\
\text { Plent }\end{array}$ & \\
\hline
\end{tabular}




\section{WILEY-BLACKWELL}

\section{INSTRUCTIONS FOR CHECKING PAGE PROOFS}

A PDF page proof of your article is provided with these instructions. Its purpose is for you to:

- Proofread your article.

- Answer any queries (which, if present, are in a query list at the end of the article).

- Check the content and positioning of tables and figures.

It is important that you check this proof very carefully and answer all the queries. Please note that only essential corrections can be made at this stage. Also note that changes you make to your article that do not comply with the style of the Journal and those that are grammatically incorrect will not be incorporated.

\section{Proofreading instructions}

Read over your article carefully, and check that:

- There are no errors in the article (including data, equations and references).

- Author and address details are accurate.

- Content and positioning of tables and figures is correct (note that some photographs in the file may appear blurry, as figures in the PDF are low resolution).

- Special characters such as figure legend symbols and Greek letters have not corrupted.

- Any previously submitted amendments have been incorporated correctly.

\section{Queries}

- Any queries are listed on the last page of the proof, with a corresponding number in the margin next to the relevant text.

- Please ensure all queries are answered in full.

\section{Return of approval to publish}

- Add corrections or answers to any queries using e-Annotation. The instructions for for using e-Annotation tools are on the following pages.

- Retain a copy of your corrections for your records.

- Email the Production Editor your approval to publish your article (either with or without amendment) and any corrections required. The Production Editor's contact details are given in the covering email.

- Prompt notification of your approval to publish your article is very much appreciated.

- Please contact the Production Editor if you have any queries. 
Required software to e-Annotate PDFs: Adobe Acrobat Professional or Adobe Reader (version 8.0 or above). (Note that this document uses screenshots from Adobe Reader $\mathbf{X}$ )

The latest version of Acrobat Reader can be downloaded for free at: http://get.adobe.com/reader/

Once you have Acrobat Reader open on your computer, click on the Comment tab at the right of the toolbar:

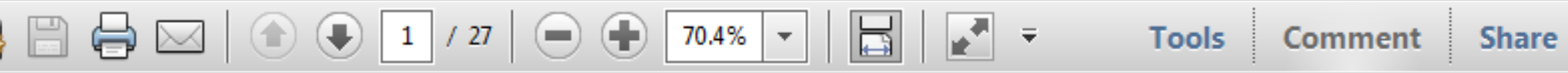

This will open up a panel down the right side of the document. The majority of tools you will use for annotating your proof will be in the Annotations section, pictured opposite. We've picked out some of these tools below:

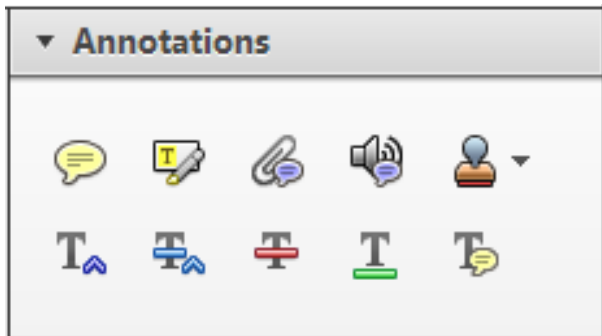

1. Replace (Ins) Tool - for replacing text.

Strikes a line through text and opens up a text box where replacement text can be entered.

How to use it

- Highlight a word or sentence.

- Click on the Replace (Ins) icon in the Annotations section.

- Type the replacement text into the blue box that appears.

Idard tramework for the analysis of $\mathrm{m}$ icy-Nevertheless, it also led to exog،

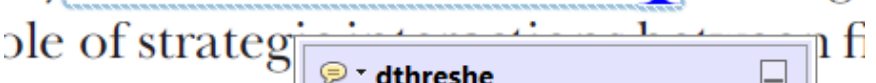
aber of comp 08/06/2011 15:58:17 $\quad$ o

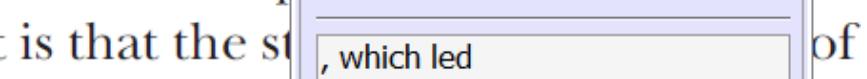
nain compo: be level, are exc nc

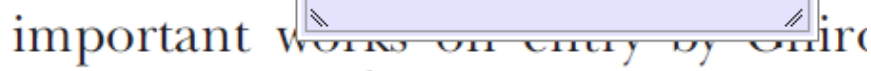
M heneferth) ${ }^{1}$ we anen the 'hlark $\mathrm{h}$

3. Add note to text Tool - for highlighting a section to be changed to bold or italic.

Tighlights text in yellow and opens up a text box where comments can be entered.

How to use it

- Highlight the relevant section of text.

- Click on the Add note to text icon in the Annotations section.

- Type instruction on what should be changed regarding the text into the yellow box that annears

namic responses of mark ups ent with the VAR evidence

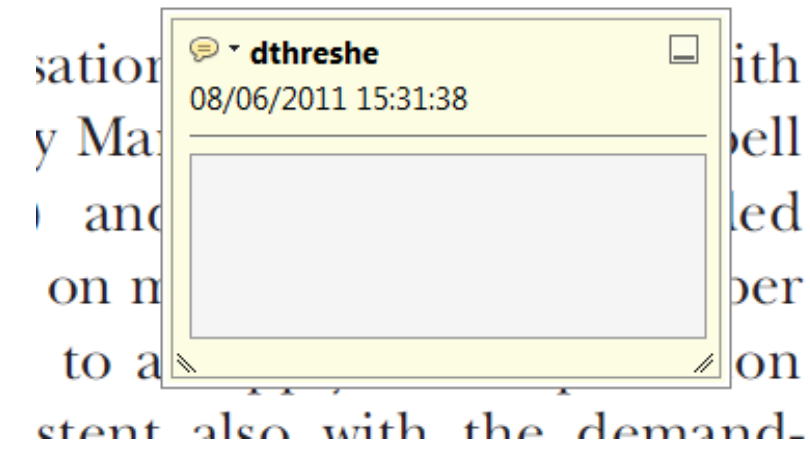

2. Strikethrough (Del) Tool - for deleting text.

Strikes a red line through text that is to be deleted.

How to use it

- Highlight a word or sentence.

- Click on the Strikethrough (Del) icon in the Annotations section.

there is no room tor extra protits al s ups are zero and the number of ret) values are not determined by Blanchard and Kiyotaki (1987), rfect competition in general equilil ts of aggregate demand and supply lassical framework assuming monol oen on evorenous nimher of firms

4. Add sticky note Tool - for making notes at specific points in the text.

Marks a point in the proof where a comment needs to be highlighted.

How to use it

- Click on the Add sticky note icon in the Annotations section.

- Click at the point in the proof where the comment should be inserted.

- Type the comment into the yellow box that appears.

ialiu ailu suppiy silucks. Iviusl ul

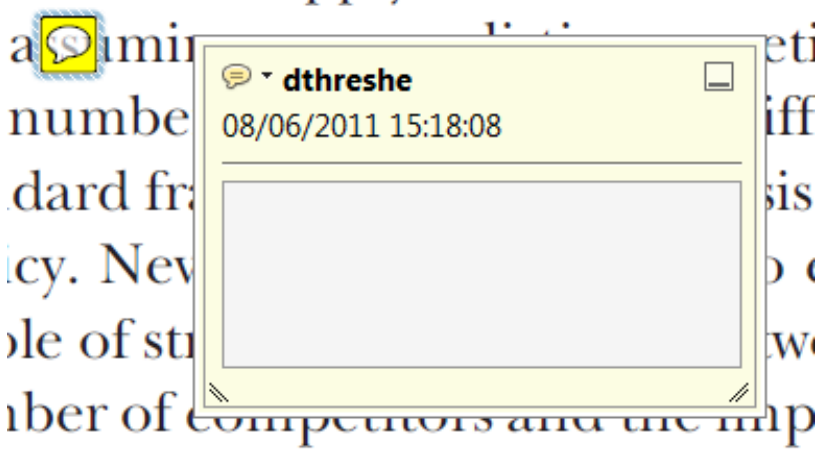

is that the structure of the secto 
5. Attach File Tool - for inserting large amounts of text or replacement figures.

Inserts an icon linking to the attached file in the appropriate pace in the text.

How to use it

- Click on the Attach File icon in the Annotations section.

- Click on the proof to where you'd like the attached file to be linked.

- Select the file to be attached from your computer or network.

- Select the colour and type of icon that will appear in the proof. Click OK.

E N D

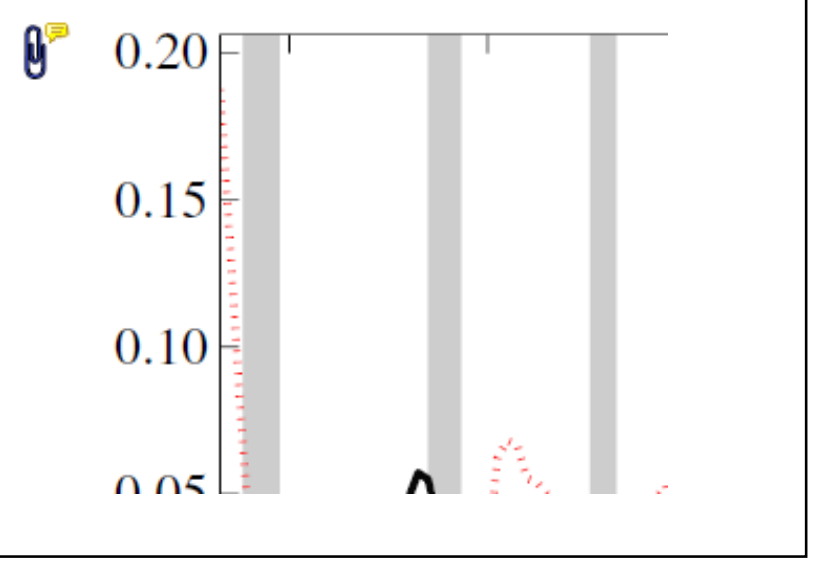

6. Add stamp Tool - for approving a proof if no corrections are required.

- Inserts a selected stamp onto an appropriate place in the proof.

\section{How to use it}

- $\quad$ Click on the Add stamp icon in the Annotations section.

- Select the stamp you want to use. (The Approved stamp is usually available directly in the menu that appears).

- Click on the proof where you'd like the stamp to appear. (Where a proof is to be approved as it is, this would normally be on the first page).

ot the Dusiness cycie, starting with the on perfect competition, constant ret

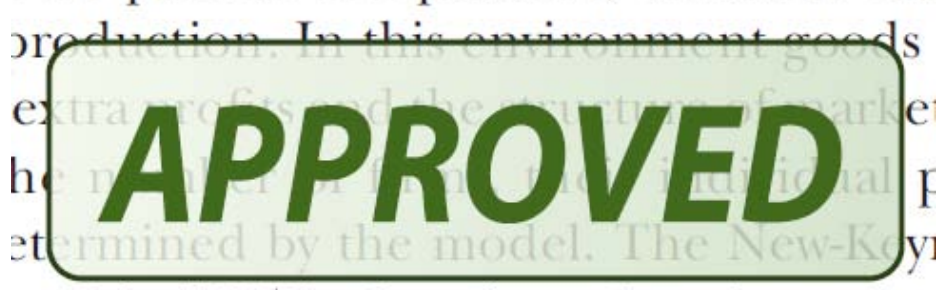
otaki (1987), has introduced produc general equilibrium models with nomin
- Drawing Markups

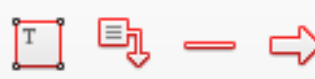

$0 \square \sqrt{6} D$

\section{How to use it}

- Click on one of the shapes in the Drawing Markups section.

- Click on the proof at the relevant point and draw the selected shape with the cursor.

- To add a comment to the drawn shape, move the cursor over the shape until an arrowhead appears.

- Double click on the shape and type any text in the red box that appears.
7. Drawing Markups Tools - for drawing shapes, lines and freeform annotations on proofs and commenting on these marks.

Allows shapes, lines and freeform annotations to be drawn on proofs and for comment to be made on these marks..

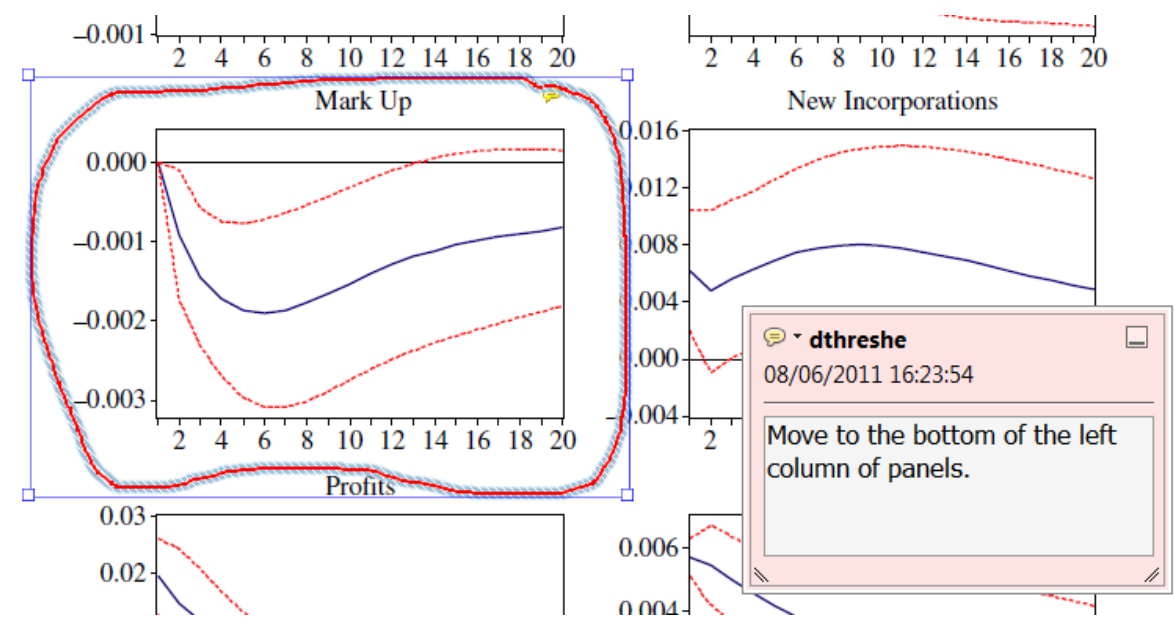

For further information on how to annotate proofs, click on the Help menu to reveal a list of further options:

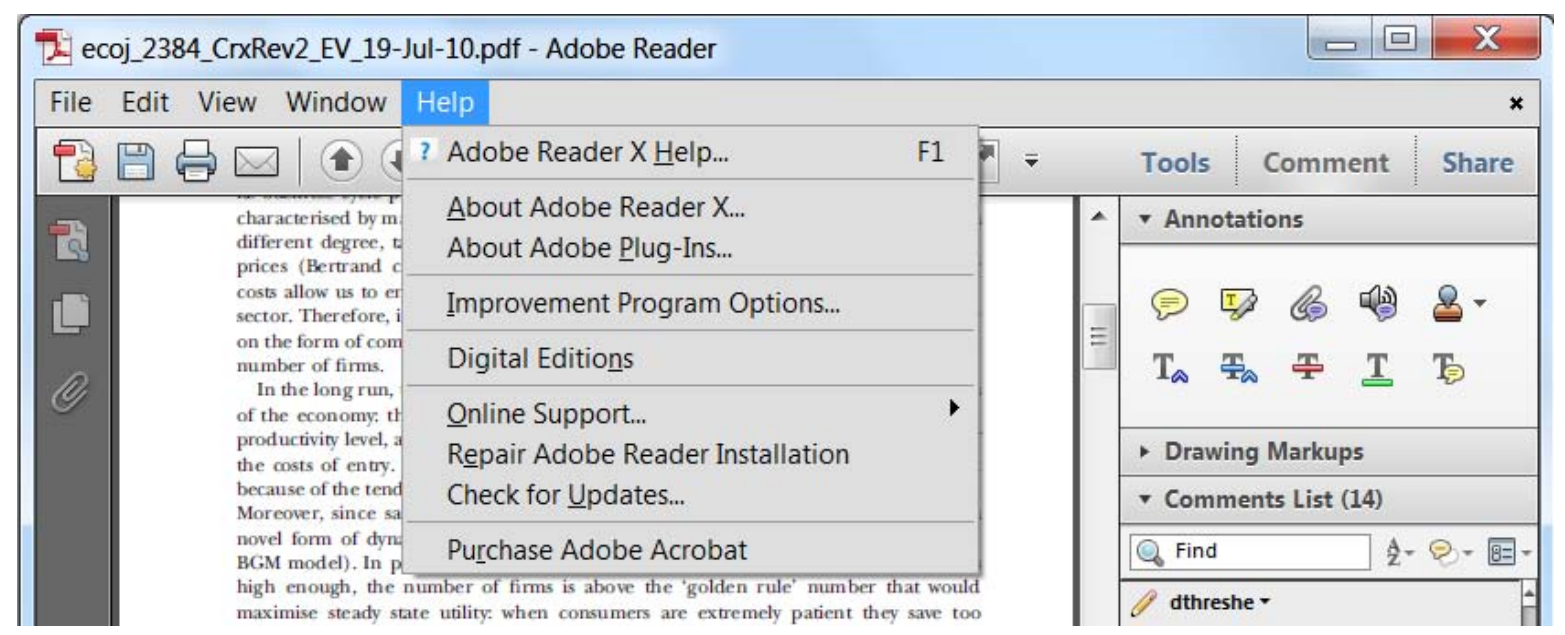


Journal of Bone and Mineral Research • 111 RIVER STREET • HOBOKEN, NJ 07030

FAX: (201) 748-6207 • E-MAIL: jbmr@wiley.com

\section{PAGE CHARGE FORM}

Per JBMR policy, page charges for published manuscripts are $\$ 60$ per page up to 8 pages and $\$ 120$ per page for the 9 th and all subsequent pages. Invited material is not subject to page fees.

Please return this form with your corrected proofs to: Sally Szymanski, e-mail: jbmr@wiley.com

JOURNAL Journal of Bone and Mineral Research

VOLUME

ISSUE

TITLE OF

MANUSCRIPT

MS. NO.

NO. OF

PAGES

$\operatorname{AUTHOR}(\mathrm{S})$

Please calculate your page charge based on the number of pages in the enclosed page proofs.

\begin{tabular}{|cc|cc|}
\hline No. of Pages & Charge (US \$) & No. of Pages & Charge (US \$) \\
\hline 1 & $\mathbf{6 0}$ & 11 & $\mathbf{8 4 0}$ \\
2 & $\mathbf{1 2 0}$ & 12 & $\mathbf{9 6 0}$ \\
3 & $\mathbf{1 8 0}$ & 13 & $\mathbf{1 , 0 8 0}$ \\
4 & $\mathbf{2 4 0}$ & 14 & $\mathbf{1 , 2 0 0}$ \\
5 & $\mathbf{3 0 0}$ & 15 & $\mathbf{1 , 3 2 0}$ \\
6 & $\mathbf{3 6 0}$ & 16 & $\mathbf{1 , 4 4 0}$ \\
7 & $\mathbf{4 2 0}$ & 17 & $\mathbf{1 , 5 6 0}$ \\
8 & $\mathbf{4 8 0}$ & 18 & $\mathbf{1 , 6 8 0}$ \\
9 & $\mathbf{6 0 0}$ & 19 & $\mathbf{1 , 8 0 0}$ \\
10 & $\mathbf{7 2 0}$ & 20 & $\mathbf{1 , 9 2 0}$ \\
\hline
\end{tabular}

Article Type (please check): $\square$ Original Article/Clinical Trials/Case Report/Clinical Vignette

TOTAL AMOUNT OF ORDER: $\$$

BILL TO:

Name

Institution

Address

\section{Purchase Order No.}

Phone

Fax

E-mail
Perspective/Review/Commentary/Viewpoint** **Invited material is not subject to page charges.

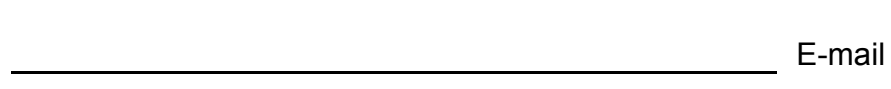




\section{COLOR CHARGE FORM}

Dear Author:

If you have requested color figures for your article to be published in an upcoming issue of the Journal of Bone and Mineral Research, kindly fill out and return this form along with your corrected proofs. Please note that invited material is not subject to color charges.

\section{Thank you.}

JOURNAL Journal of Bone and Mineral Research

VOLUME

ISSUE

\section{TITLE OF}

MANUSCRIPT

MS. NO.

NO. OF

PAGES

$\operatorname{AUTHOR}(\mathrm{S})$

\begin{tabular}{|c|c|c|c|}
\hline No. Color Pages & Color Charges & No. Color Pages & Color Charges \\
\hline 1 & $\$ 900$ & 5 & $\$ 4500$ \\
2 & $\$ 1800$ & 6 & $\$ 5400$ \\
3 & $\$ 2700$ & 7 & $\$ 6300$ \\
4 & $\$ 3600$ & $\mathbf{8}$ & $\$ 7200$ \\
\hline
\end{tabular}

Article Type (please check): $\square$ Original Article/Clinical Trials/Case Report/Clinical Vignette

TOTAL AM OUNT OF ORDER: \$

BILL TO:

Name

Institution

Address

\section{Purchase}

Order No.

\section{Phone}

Fax

E-mail
Perspective/Review/Commentary/Viewpoint**

**Invited material is not subject to page charges. 


\section{(3)WILEY-BLACKWELL}

Additional reprint and journal issue purchases

Should you wish to purchase additional copies of your article, please click on the link and follow the instructions provided: https://caesar.sheridan.com/reprints/redir.php?pub=10089\&acro=JBMR

Corresponding authors are invited to inform their co-authors of the reprint options available.

Please note that regardless of the form in which they are acquired, reprints should not be resold, nor further disseminated in electronic form, nor deployed in part or in whole in any marketing, promotional or educational contexts without authorization from Wiley. Permissions requests should be directed to mailto: permissionsus@wiley.com

For information about 'Pay-Per-View and Article Select' click on the following link: http://wileyonlinelibrary.com/ppv 